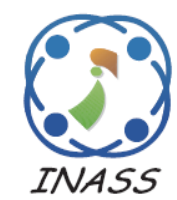

\title{
Corner Truncated Triple Band Notch Monopole with DGS for Satellite Communication Applications
}

\author{
Vysyaraju Lokesh Raju ${ }^{1,2 *}$ \\ Valluri Rajya Lakshmi ${ }^{3}$ \\ Mosa Satya Anuradha ${ }^{1}$ \\ ${ }^{I}$ Department of Electronics and Communication Engineering, Andhra University, Visakhapatnam, AP, India \\ ${ }^{2}$ Department of Electronics and Communication Engineering, \\ Aditya Institute of Technology and Management, Tekkali, AP, India \\ ${ }^{3}$ Department of Electronics and Communication Engineering, \\ Anil Neerukonda Institute of Technology and Sciences, Sangivalasa, Visakhapatnam, AP, India \\ * Corresponding author's Email: lokeshrajuv22@gmail.com
}

\begin{abstract}
A Compact triple notch band monopole antenna with defected ground structure is proposed in this article. Corner truncated square radiating element on the top side and defected ground structure on the bottom side are placed on FR4 substrate of permittivity 4.4. An inverted U-slot is placed on the feed line to have proper impedance between feed point and the ground plane. The proposed antenna providing triple notch band characteristics between 7-7.4 GHz, 8-12 GHz and 16-18 GHz respectively. The fabricated antenna occupying the dimension of $24 \mathrm{X} 26 \mathrm{X} 1.6$ $\mathrm{mm}$ and the measured results providing excellent correlation with simulation results.
\end{abstract}

Keywords: Corner truncated (CT), Defected ground structure (DGS), Triple notch, Voltage standing wave ratio (VSWR), Wireless local area network (WLAN).

\section{Introduction}

The advancements in the wideband technology enabling high data transmission rate for indoor and outdoor communications with low power consumption. The simple hardware configuration making this wideband technology as unique advantageous solution over conventional narrow band technology. Nevertheless, the UWB system still facing different challenges like interference to WLAN operating in the IEEE WiMAX network 3.35-GHz (3.3-3.4 GHz), 3.5-GHz (3.4-3.6 GHz), 3.7-GHz (3.6-3.8 GHz) (5.725-5.85 GHz), WLAN $5.25-\mathrm{GHz}(5.15-5.35 \mathrm{GHz})$ and $5.75-\mathrm{GHz}(5.725-$ $5.825 \mathrm{GHz})$, IEEE INSAT/Super-Extended C-band, and $\mathrm{X}$-band 7.5-8.5 GHz operating bands. Researchers are designing different antennas with multiband characteristics for compact and handheld devices for multi service systems.

In literature single band, dual band, triple band and multiband notch antennas with compact dimensions are available [1 - 4]. Antenna models for bandwidth enhancement through defected ground structures are proposed with microstrip line, coplanar waveguide feeding, and aperture coupled feeding for wireless communication applications [5 7]. However, the notch weights of most reported antennas are relatively too wide, which may lead to wastage of useful frequencies. To achieve compactness as well as wideband characteristics in the design, fractal geometry is used because of its self-similar and space healing properties. [8 - 10]. To achieve the reconfigurable performance in rejection bands, different types of switches such as RF MEMS, RF MESFET, Varactor diodes and $\mathrm{p}-\mathrm{i}-\mathrm{n}$ diodes are used [11 - 14].

In this article, a triple notch reconfigurable monopole antenna is designed with defected ground structure. In this design, the radiating element lower side and the defected ground upper side are etched with corner truncated slots. To get single notch band characteristics from the wideband antenna, an 
Table 1. Comparison with Literature

\begin{tabular}{|c|c|c|c|}
\hline Ref. No & $\begin{array}{l}\text { Antenna size } \\
(\mathrm{mm})\end{array}$ & $\begin{array}{c}\text { Notching } \\
\text { Bands in } \mathrm{GHz}\end{array}$ & $\begin{array}{c}\text { Average } \\
\text { Gain in } \\
\mathrm{dB}\end{array}$ \\
\hline 1 & $34 \times 36 \times 1.6$ & $\begin{array}{l}\text { Single band } \\
\text { notching (5.1- } \\
6.05)\end{array}$ & 2.84 \\
\hline 2 & $24 X 26 \times 1.6$ & $\begin{array}{c}\begin{array}{c}\text { Dual band } \\
\text { notching }\end{array} \\
\text { WiMAX }(3.4- \\
3.6 \mathrm{GHz}) \text { and } \\
\text { WLAN }(5.15- \\
5.85 \mathrm{GHz})\end{array}$ & 2.6 \\
\hline 3 & $32 X 34 X 1.6$ & $\begin{array}{c}\text { Triple band } \\
\text { notching 3.39- } \\
3.88 \mathrm{GHz}, \\
5.11- \\
5.97 \mathrm{GHz} \text {, and } \\
8.0-8.71 \mathrm{GHz}\end{array}$ & 2.5 \\
\hline 4 & $36 \times 24 \times 1.6$ & $\begin{array}{c}\text { Dual band } \\
\text { notching } 2.8- \\
3.2 \mathrm{GHz} \text { and } \\
3.6-5 \mathrm{GHz}\end{array}$ & 3.2 \\
\hline 14 & $20 \times 17.6 \times 1.6$ & $\begin{array}{c}\begin{array}{c}\text { Dual band } \\
\text { notching }\end{array} \\
\text { WIMAX }(3.1- \\
3.9 \mathrm{GHz}) \text { and } \\
\text { WLAN }(5.1- \\
5.9 \mathrm{GHz})\end{array}$ & 2.4 \\
\hline 15 & $32 \times 36 \times 1.6$ & $\begin{array}{c}\text { Triple Band } \\
\text { Notching (3-4 } \\
\text { GHz, 5-7 GHz } \\
\text { and } 8-11 \mathrm{GHz})\end{array}$ & 2.6 \\
\hline 16 & $38 X 42 X 1.6$ & $\begin{array}{l}\text { Triple Band } \\
\text { Notching (8- } \\
8.6 \mathrm{GHz}, 9.2- \\
10 \mathrm{GHz} \text { and } \\
12-14 \mathrm{GHz})\end{array}$ & 2.5 \\
\hline 17 & $38 X 40 X 1.6$ & $\begin{array}{l}\text { Triple Band } \\
\text { Notching (5-8 } \\
\mathrm{GHz}, 9-11.5 \\
\mathrm{GHz} \text { and } 12-13 \\
\mathrm{GHz})\end{array}$ & 2.8 \\
\hline $\begin{array}{c}\text { Proposed } \\
\text { Antenna }\end{array}$ & 24X26X1.6 & $\begin{array}{c}\text { Triple band } \\
\text { notching 7-7.4 } \\
\text { GHz, 8-12 } \\
\text { GHz and 16-18 } \\
\text { GHz }\end{array}$ & 3.4 \\
\hline
\end{tabular}

inverted u-shaped slot is placed in the radiating element. To attain dual notch band characteristics, two inverted u-shaped slots and to achieve triple notch band characteristics, three inverted u-shaped slots are placed on the radiating structure. The current model is fabricated on FR4 substrate of thickness $1.6 \mathrm{~mm}$ and tested the results for notch bands at desired frequency bands as well as reconfigurable characteristics on vector network analyzer. A comparison between the literature and the current antenna model is presented in Table 1. The design aspects of the antenna and its dimensional characterization with mathematical formulation is given in section 2 of antenna geometry. The section 3 will provide the detailed design methodology in the step wise. The section 4 will provide the results and analysis with respect to radiation characteristics, surface current distribution and measurement results of the proposed antenna with tunable behaviour in the detailed manner.

\section{Antenna geometry}

The designed antenna is constructed on FR4 substrate of $\varepsilon_{\mathrm{r}}=4.4$ with overall dimension of 26X24X1.6 mm. The patch consisting of square shaped radiating element with corner truncation at lower edges. Inverted U-shaped slots are placed on the radiating element to achieve the notch band characteristics in the antenna operating band. The ground plane is partially etched and made defected ground to obtain good impedance bandwidth. The ground plane was selected in a fashion with corner truncated orientation on top edges. A 50-ohm input impedance is used at the port to attain good impedance matching. The structure of the antenna and its iterations are presented in Fig. 1. A basic antenna without slots is working in the wideband is modified as single notch monopole as shown in the Fig. 1 (a) with the placement of inverted U-shaped slot in the radiating structure. Double notch band and the triple notch band characteristics are obtained by the placement of additional slots in the radiating patch as shown in Figs. 1 (b) and (c). The dimensional characteristics are presented in Table 1.

The effective dielectric permittivity of the narrow microstrip line is expressed as

$$
\epsilon_{r e}=\frac{\epsilon_{r}+1}{2}+\frac{\epsilon_{r}+1}{2} \frac{\operatorname{In}\left(\frac{\pi}{2}\right)+\left(1 / \epsilon_{r}\right) \operatorname{In}\left(\frac{4}{\pi}\right)}{\operatorname{In}(8 h / W)}
$$

The wavelength of the signal propagating through a microstrip line is

$$
\lambda_{m}=\frac{\lambda_{0}}{\sqrt{\epsilon_{r e}}}
$$

The characteristic impedance can be calculated from the Eqs. (3) and (4). 


$$
\begin{gathered}
Z_{\text {om }}=\frac{\eta}{2 \pi \sqrt{\epsilon_{r e}}} \operatorname{In}\left(\frac{8 h}{W}+0.25 \frac{W}{h}\right) \text { for } \mathrm{w} / \mathrm{h}>1 \\
Z_{\text {om }}=\frac{\eta}{2 \pi \sqrt{\epsilon_{r e}}}\left\{\frac{W}{h}+1.393+0.667 \operatorname{In}\left(\frac{W}{h}+1.444\right)\right\}^{-1} \\
\text { for } \mathrm{w} / \mathrm{h}<1
\end{gathered}
$$

When the characteristic impedance of the microstrip line is known then to find the width of the strip

$\frac{W}{h}=\frac{2}{\pi}\left\{\frac{60 \pi^{2}}{Z_{o m} \sqrt{\epsilon_{r}}}-1-\operatorname{In}\left(\frac{120 \pi^{2}}{Z_{\text {om }} \sqrt{\epsilon_{r}}}-1\right)+\frac{\epsilon_{r}+1}{2 \epsilon_{r}}\left[\operatorname{In}\left(\frac{60 \pi^{2}}{Z_{\text {om }} \sqrt{\epsilon_{r}}}-1\right)+0.39-\frac{0.61}{\epsilon_{r}}\right]\right\}$

This expression will give the effective length of the radiating patch.

$$
f_{r}=\frac{1}{2 L \sqrt{\epsilon_{r e}} \sqrt{\epsilon_{0} \mu_{0}}} \sqrt{\frac{2}{\epsilon_{r}+1}}
$$

For an efficient radiator, the optimized width is given as

$$
W=\frac{1}{2 f_{r} \sqrt{\epsilon_{0} \mu_{0}}} \sqrt{\frac{2}{\epsilon_{r}+1}}
$$

The length of the patch can be determined by

$$
L=\frac{1}{2 f_{r} \sqrt{\epsilon_{r e}} \sqrt{\epsilon_{0} \mu_{0}}}-2 \Delta L
$$

Here ' $\mathrm{f}_{\mathrm{r}}$ ' is the resonating frequency.

\section{Design methodology}

The design procedure of the antenna started by finding the dimensions of the feeding element with 50-ohm characteristic impedance. The defected ground plane upper part is also truncated for impedance matching and to attain good bandwidth. An inverted $u$-shaped slot is placed on the radiating element to achieve single notch band at WLAN band. Dual notch band is achieved with dual inverted u-slots and triple notch band is achieved with triple inverted u-slots on the patch element.

\subsection{Step 1:}

A square monopole with corner truncated at lower portion is designed with microstrip feeding. Defected ground structure with upper corner truncated is used and to get impedance matching with the radiating structure another slot is placed in the feed line. A u-slot is etched on the radiating element to notch x-band as shown in the Fig. 2 (a). The corresponding reflection coefficient and the VSWR can be observed from Fig. 2 (b). The approximated length of the slot is estimated using the Eq. (9), where 'c' is the velocity of the light.

$$
L_{\text {notch }}=\frac{c}{2 f_{\text {notch }} \sqrt{\epsilon_{\text {eff }}}}
$$

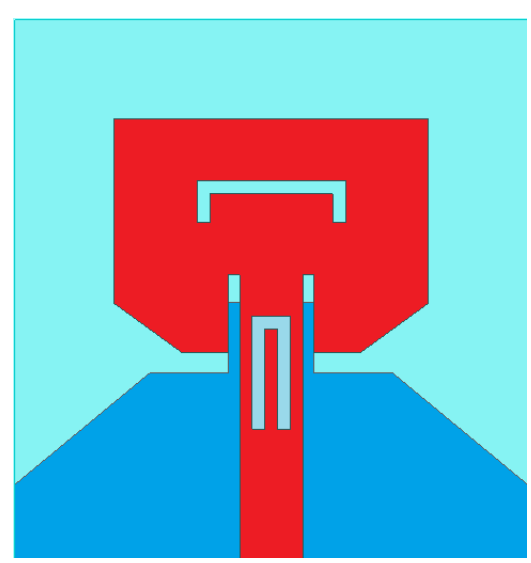

(a)

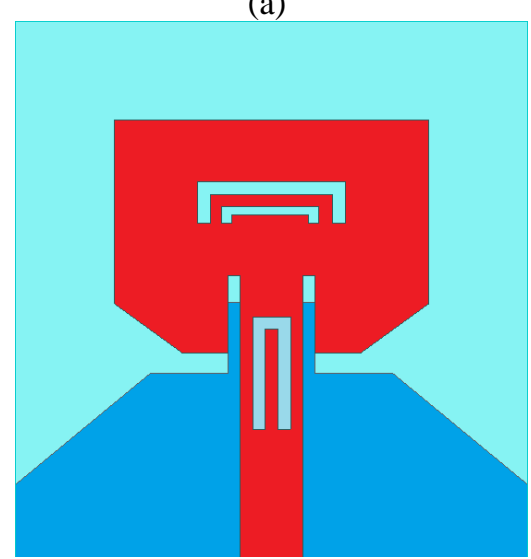

(b)

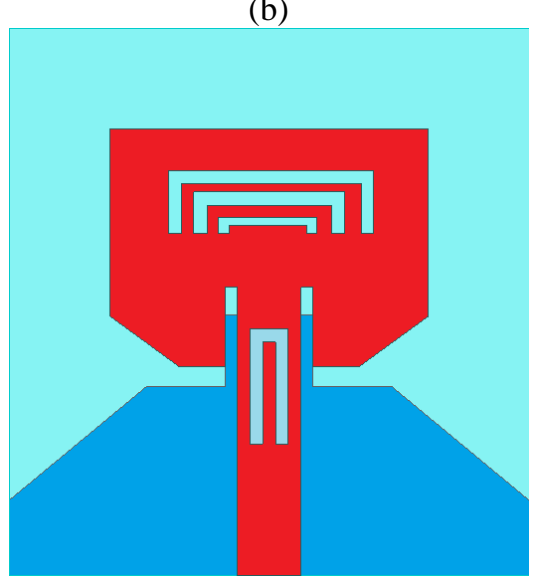

(c)

Figure. 1 Antenna iterations: (a) single notch monopole, (2) dual notch monopole, and (c) triple notch monopole 


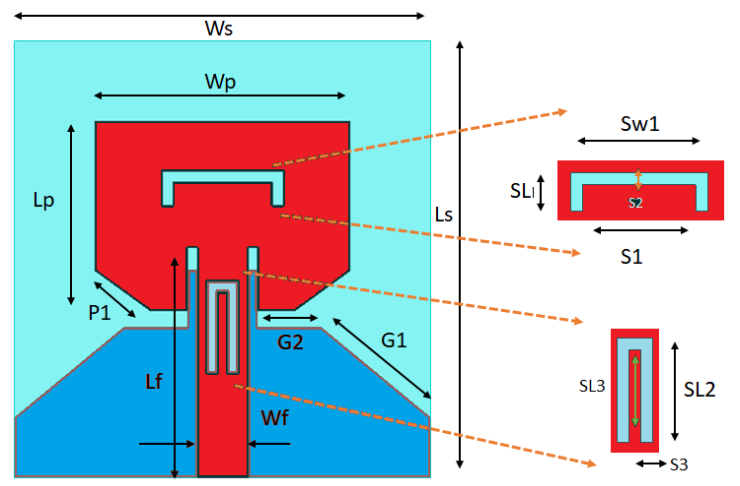

(a)

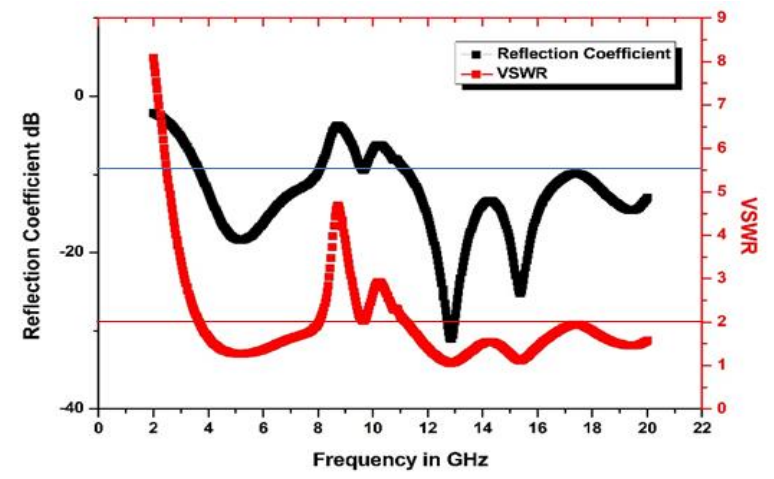

(b)

Figure. 2 Single notch monopole: (a) dimensional view of single notch monopole and (b) reflection coefficient \& VSWR vs. frequency

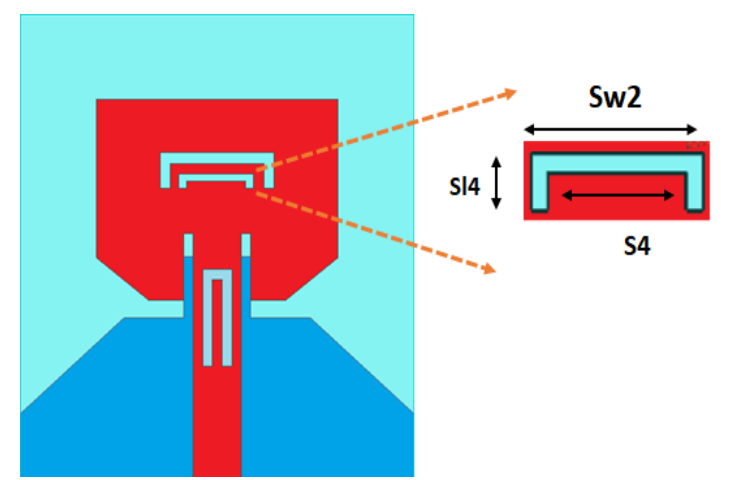

(a)

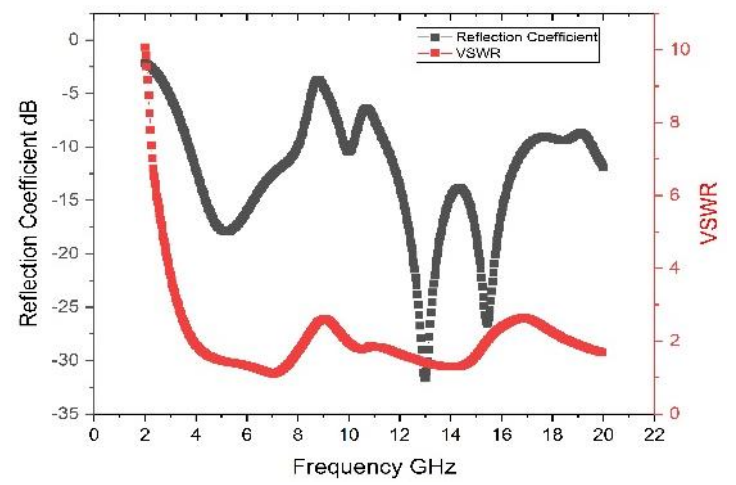

(b)

Figure. 3 Dual notch monopole: (a) dimensional view of dual notch monopole and (b) reflection coefficient \& VSWR vs. frequency

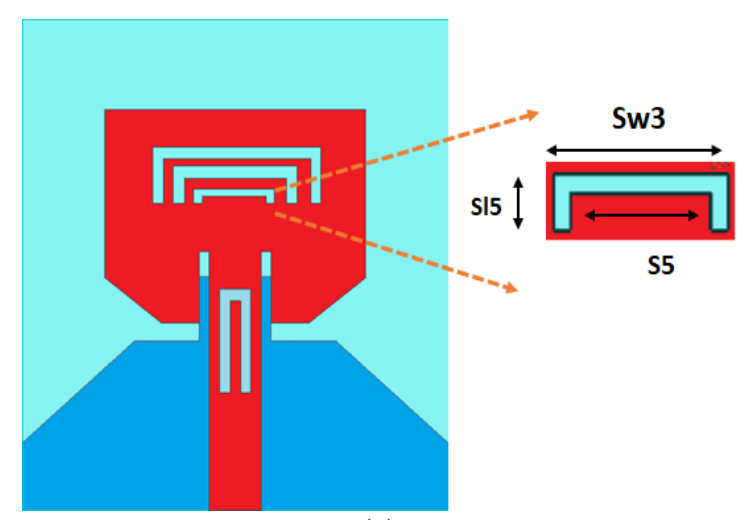

(a)

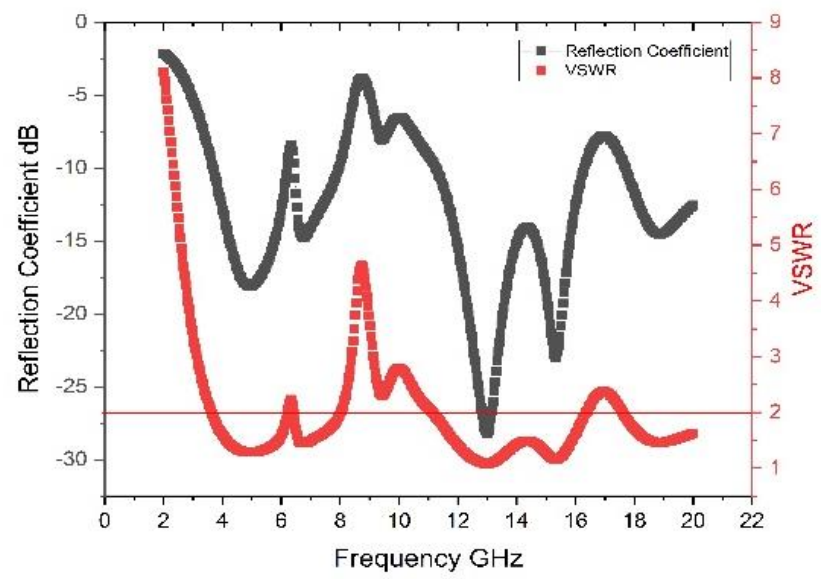

(b)

Figure. 4 Triple notch monopole: (a) dimensional view of triple notch monopole and (b) reflection coefficient \& VSWR vs. frequency

\subsection{Step 2:}

A single notch band model is modified with dual notch band model by placing one more inverted $\mathrm{u}$ shaped slot below the existing slot. The dimensions of the second slot are presented in the antenna dimensions table. The characteristics of the reflection coefficient and the VSWR for the dual notch antenna is presented in Fig. 3 (b). Dual notching is obtained at $\mathrm{x}$-band $(8-12 \mathrm{GHz})$ and $17-$ $20 \mathrm{GHz}$ respectively. The operating bands are from 4-8 $\mathrm{GHz}$ and $12-17 \mathrm{GHz}$ with minimum reflection coefficient of $-33 \mathrm{~dB}$ at $13 \mathrm{GHz}$.

\subsection{Step 3:}

The dual notch band model is modified with triple notch band model by placing one more inverted $\mathrm{u}$-shaped slot below the existing slots. The dimensions of the third slot are presented in the antenna dimensions Table 2. The characteristics of the reflection coefficient and the VSWR for the triple notch antenna is presented in Fig. 4 (b). Triple notching is obtained at $7-7.4 \mathrm{GHz}, 8-12 \mathrm{GHz}$ and 
Table 2. Antenna dimensions in $\mathrm{mm}$

\begin{tabular}{|c|c|c|c|c|c|c|c|c|c|c|}
\hline Ws & Ls & Wp & Lp & Wf & Lf & G1 & G2 & Sw2 & S14 & S4 \\
\hline 24 & 26 & 15.2 & 9.2 & 3 & 13.4 & 6.6 & 3.8 & 7.2 & 2 & 5.9 \\
\hline P1 & S1 & S2 & S3 & SL1 & SL2 & SL3 & Sw1 & Sw3 & S15 & S5 \\
\hline 2.4 & 8.6 & 0.6 & 0.3 & 3 & 5.8 & 5.5 & 9.8 & 4.7 & 1 & 3.6 \\
\hline
\end{tabular}

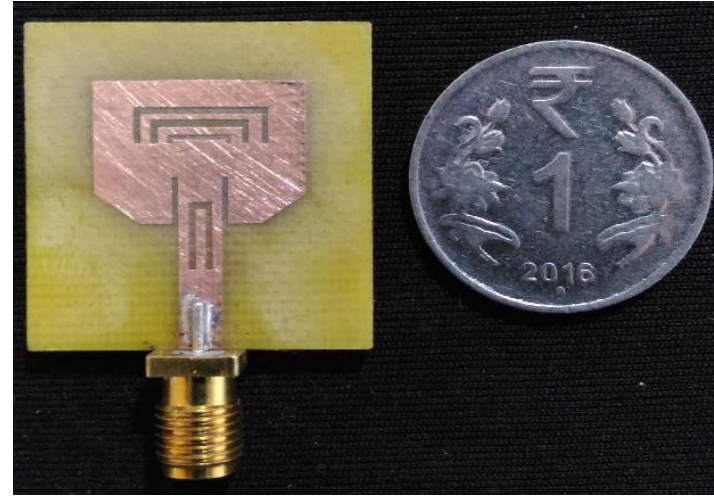

(a)

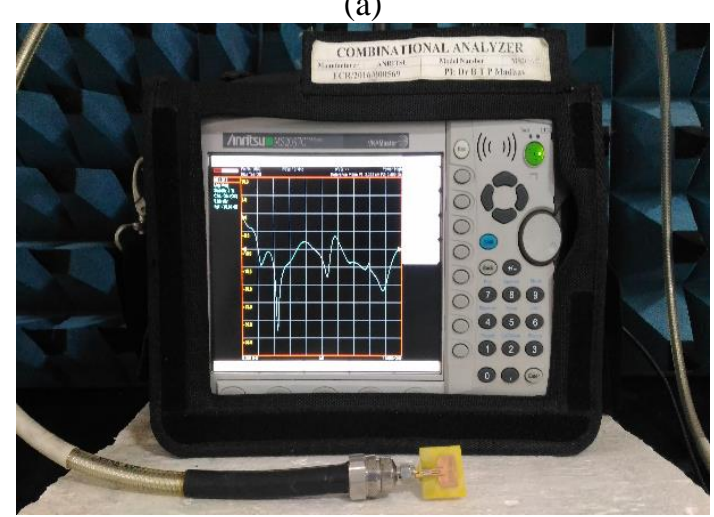

(b)

Figure. 5 Prototyped triple notch antenna: (a) fabricated antenna and (b) measurement of $S_{11}$

16-18 GHz respectively. The operating bands are from $4-6 \mathrm{GHz}, 7.4-8 \mathrm{GHz}$ and $11-16 \mathrm{GHz}$ with minimum reflection coefficient of $-28 \mathrm{~dB}$ at $13 \mathrm{GHz}$. The prototyped triple notch antenna can be observed in Fig. 5.

\section{Results and discussion}

To design the triple notch band antenna, initially an antenna capable of covering ultra-wideband range is designed. After that, notch band characteristics are introduced with the placement of inverted u-slots in the radiating structure. All parameters of the antenna are optimized with high frequency structural simulator HFSS tool. Iteration wise analysis is presented in this section and the optimized model is fabricated. The measured results on vector network analyzer and in anechoic chamber are providing good correlation with the simulation results for validation.

The measured radiation patterns of the dual notch band antenna and the triple notch band antenna are presented in Fig. 6. Dual notch band antenna is showing directive pattern at $4.5 \mathrm{GHz}$ and monopole like radiation at 13 and $15 \mathrm{GHz}$ in the Eplane. Quasi omni directional pattern can be observed in the H-plane. The triple notch band antenna is also showing similar kind of radiation characteristics like dual notch band antenna at 4.5, 13 and $15 \mathrm{GHz}$ respectively.

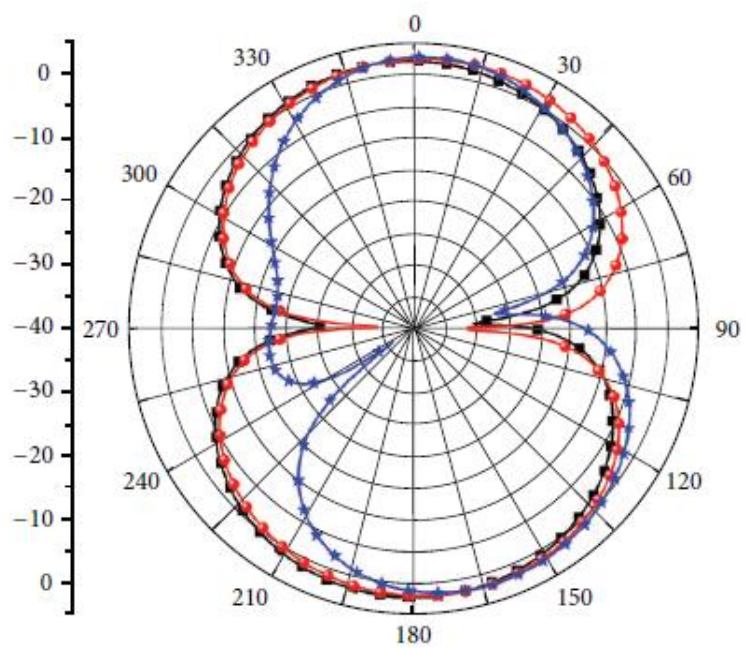

(a)

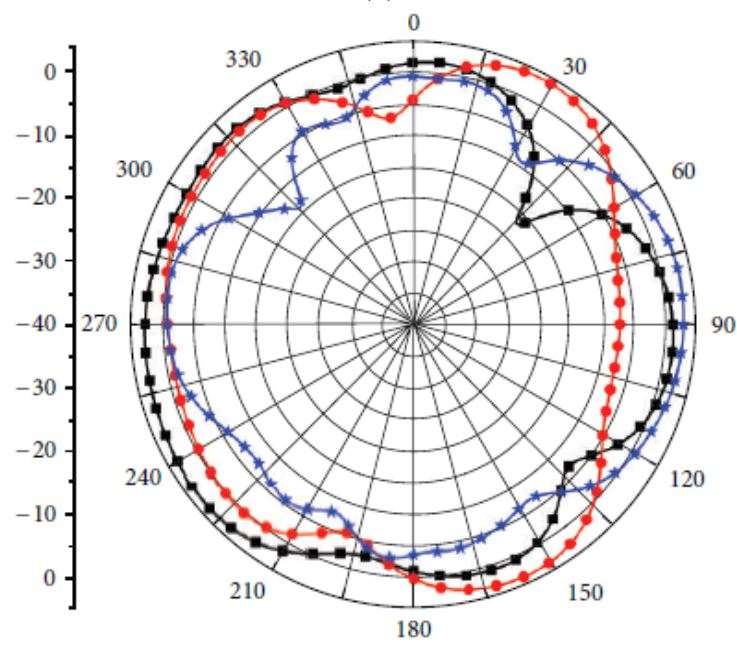

(b) 


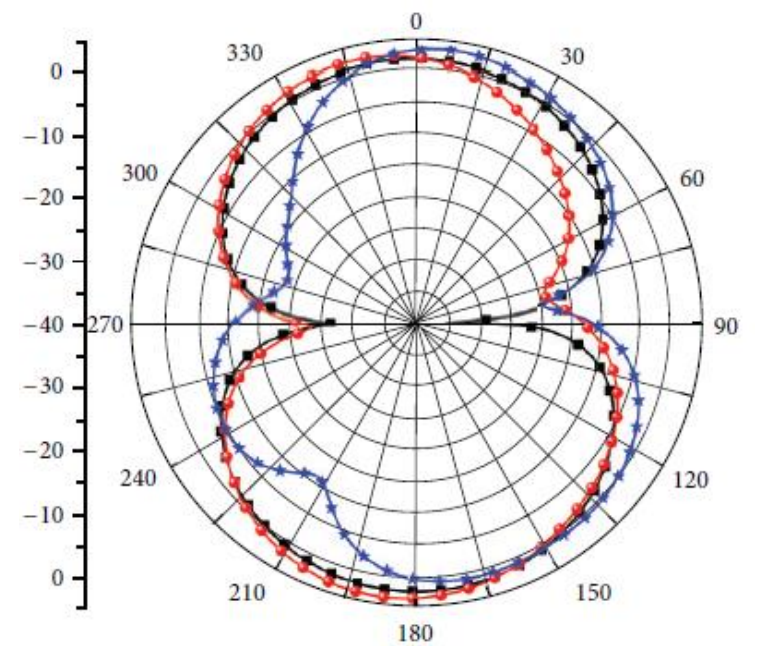

(c)

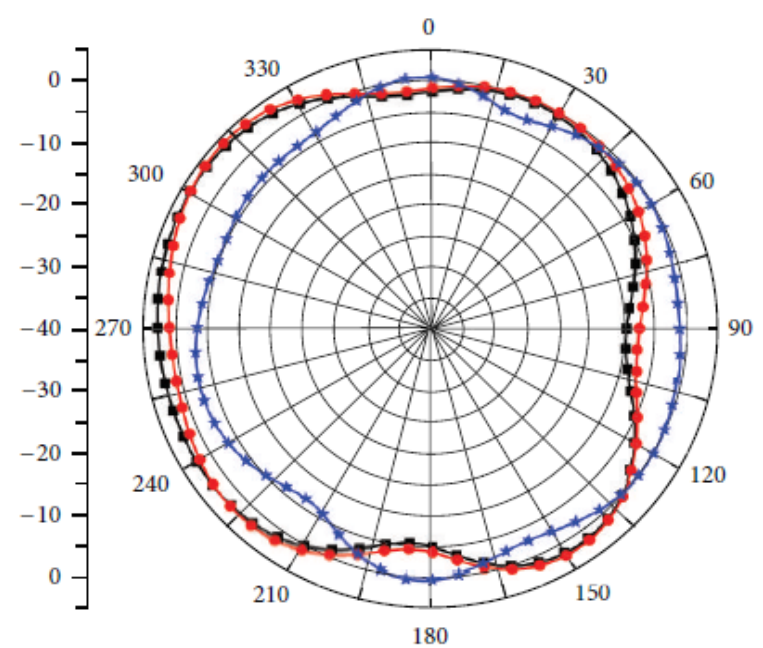

(d)

Figure. 6 Radiation characteristics of the dual and triple notch antenna models: (a) E-Plane pattern of dual notch monopole, (b) H-Plane pattern of dual notch monopole (4.5 GHz, $13 \mathrm{GHz}$ and $15 \mathrm{GHz}$ ), (c) E-Plane pattern of triple notch monopole, and (d) H-Plane pattern of triple notch monopole $(4.5 \mathrm{GHz}, 13 \mathrm{GHz}$ and $15 \mathrm{GHz})$

The surface current distribution characteristics of the triple notch band antenna is shown in Fig. 7. At $4.5 \mathrm{GHz}$ the current density is more from first slot and the lower corners of the radiating structure. At $7 \mathrm{GHz}$ and $13 \mathrm{GHz}$ the radiation is from the feed line. At $15 \mathrm{GHz}$ around third slot the current elements are having equal magnitude but flowing in opposite direction resulting no radiation. This causing the third notch band in the operating band.

\subsection{Reconfigurability}

To achieve tunable notch band, a pin diode of BAR $64-02 \mathrm{v}$ is mounted on the slots of radiating

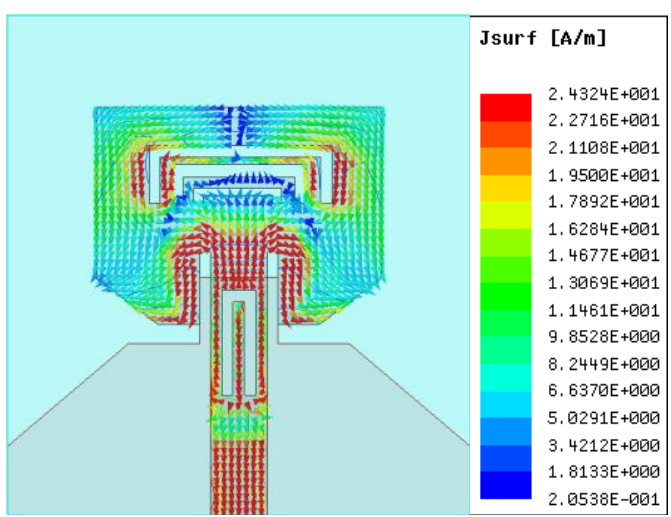

(a)

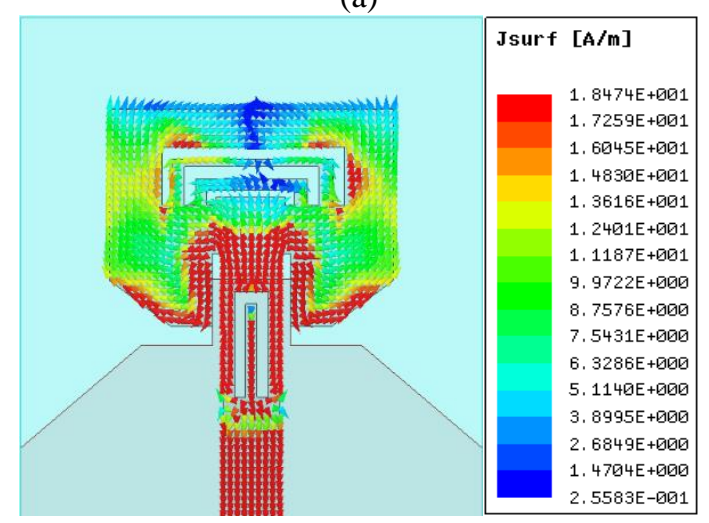

(b)

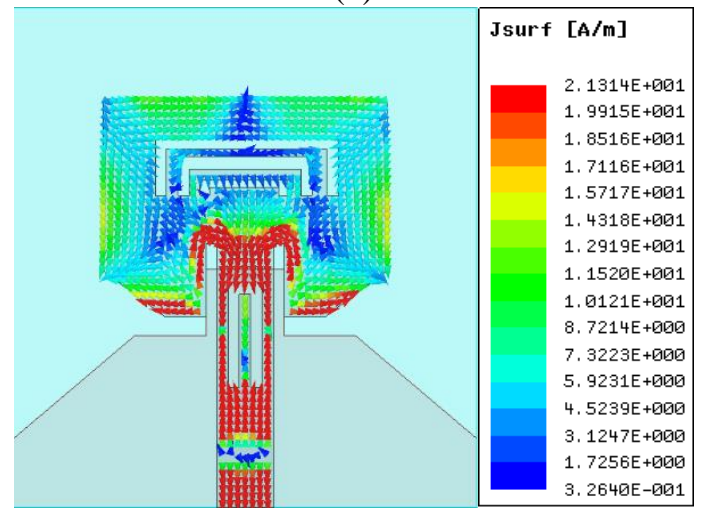

(c)

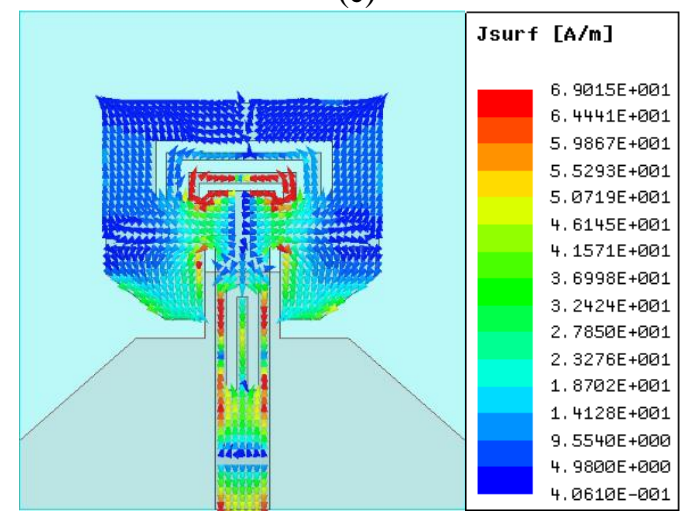

(d)

Figure. 7 Surface current distribution of the triple notch band monopole: (a) at $4.5 \mathrm{GHz}$, (b) at $7 \mathrm{GHz}$, (c) at 13 $\mathrm{GHz}$, and (d) at $15 \mathrm{GHz}$ 
element as shown in Fig. 8. The variation in the voltage of the pin diode gradually changes the effective electrical length of the resonator and resulting in a continuously to tunable notch band. Three diodes are placed at three slots and based on the switching condition of the diodes, the reconfigurability is examined and reported. Table 2 gives the reconfigurable behaviour of the antenna with diodes switching condition. The prototyped antenna front, back view and the testing of reconfigurability on combinational analyzer is presented in Figs. 9 and 10.

The prototyped antenna with diodes placement and the biasing connection can be observed from Fig. 10. The Fig. 11 shows the reconfigurable behaviour of the antenna VSWR characteristics with change in the diode switching conditions. When diodes are in off condition, triple notch band characteristics are attained and when all the diodes are in on condition and in off condition, the VSWR behaviour of the antenna is found exactly same. When D1 and D3 are on and D2 is off, the designed antenna is showing triple notch band characteristics with shift in the bands to lower frequency. In this condition, Triple Notching occurred at $6-8.5,9-10$ and $11-14.5 \mathrm{GHz}$ respectively. When D1 and D2 are off and D3 is on,

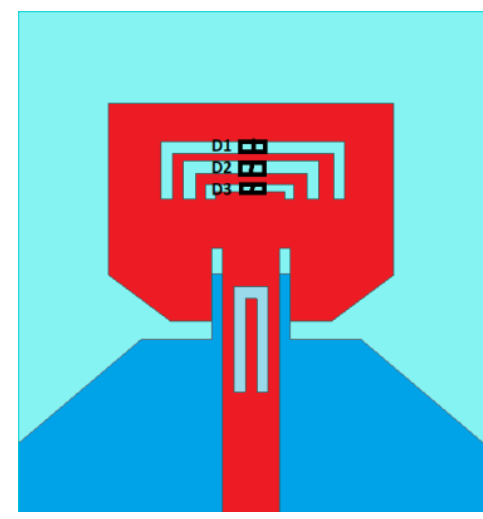

(a)

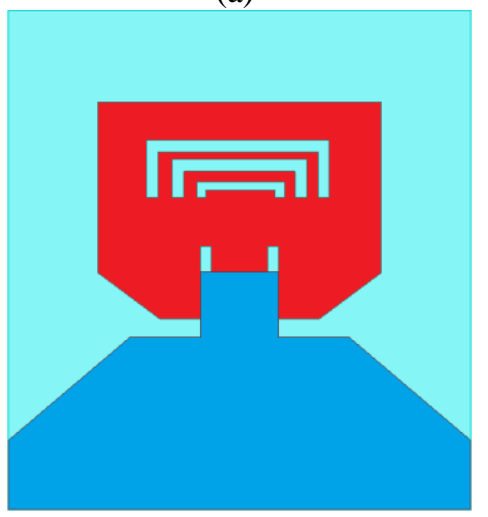

(b)

Figure. 8 Triple notch antenna with PIN diodes at slots: (a) top view and (b) bottom view

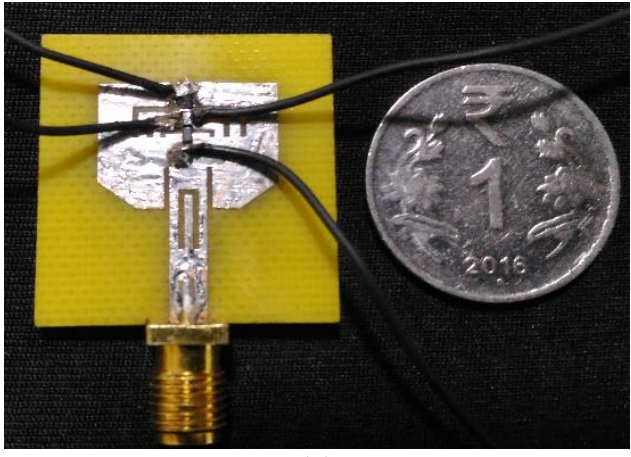

(a)

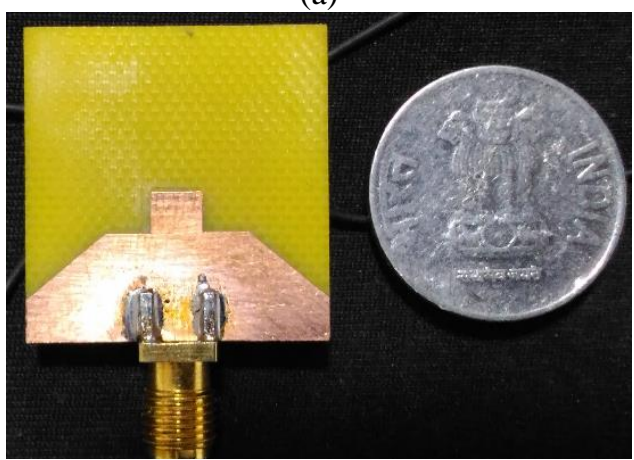

(b)

Figure. 9 Triple notch antenna connected to diodes and biasing lines: (a) top side and (b) bottom side

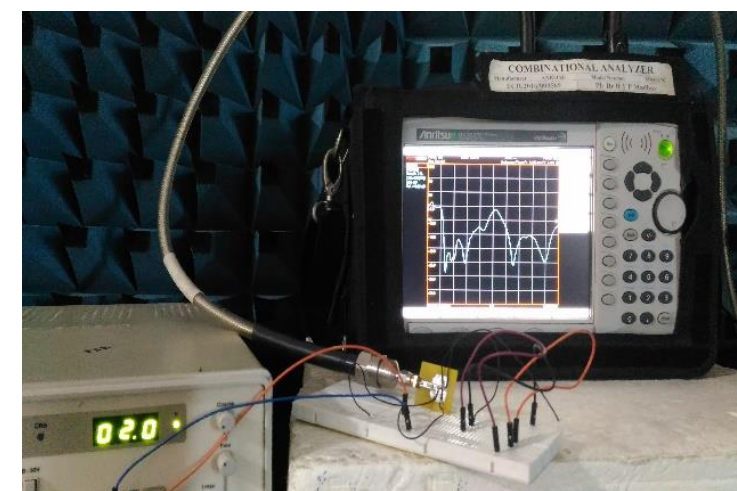

Figure. 10 Measurement of frequency reconfigurability

dual notch bands are obtained at $8-10 \mathrm{GHz}$ and 15 18.5 GHz. When D1is off and D2 and D3 are on then antenna showing single notch band at higher frequency band of $17-18 \mathrm{GHz}$.

\section{Conclusion}

A compact triple notch reconfigurable antenna is designed in this work and presented the analysis. The proposed antenna is constructed on FR4 substrate of permittivity 4.4 and occupying the total size of 24X26X1.6 mm. The reconfigurable behavior of the antenna is tested by placing BAR $64-02 \mathrm{v}$ diodes on the etched slots of the radiating structure and biasing voltage is applied. The prototyped antenna is tested in the anechoic chamber with connection to combinational analyzer 
and regulated power supply for frequency reconfigurable behavior and obtained the good correlated results with the simulation from HFSS tool. These testing results providing validation and confidence to apply the antenna in real time environment for desired band applications.

The design with tunable notch band behavior is possible for antenna frequency bands only. The polarization reconfigurability, pattern reconfigurability and hybrid reconfigurability can be attained with the novel structures of cross slot techniques and with other types of feeding methods. The performance characteristics with respect to the gain and the radiation characteristics to be examined with new optimization techniques in the future.

Table 3. Reconfigurable behaviour with diodes switching

\begin{tabular}{|c|c|c|c|c|c|c|}
\hline $\begin{array}{l}\text { S. } \\
\text { No }\end{array}$ & D1 & D2 & D3 & $\begin{array}{l}\text { Notch } \\
\text { Bands } \\
(\mathrm{GHz})\end{array}$ & $\begin{array}{l}\text { Average } \\
\text { Gain } \\
(\mathrm{dB}) \\
\end{array}$ & $\begin{array}{l}\text { Average } \\
\text { Efficiency } \\
(\%)\end{array}$ \\
\hline 1 & 0 & 0 & 0 & $\begin{array}{l}\text { Triple } \\
\text { Notch } \\
(7-7.4, \\
8-12 \\
\text { and 16- } \\
18 \\
\text { GHz) }\end{array}$ & $3.4 \mathrm{~dB}$ & $76 \%$ \\
\hline 2 & 0 & 0 & 1 & $\begin{array}{l}\text { Dual } \\
\text { Notch } \\
(8-10 \\
\text { and 15- } \\
18.5 \\
\text { GHz) }\end{array}$ & $2.7 \mathrm{~dB}$ & $67 \%$ \\
\hline 3 & 0 & 1 & 0 & $\begin{array}{l}\text { Single } \\
\text { Notch } \\
8-10 \\
\mathrm{GHz}\end{array}$ & $2.9 \mathrm{~dB}$ & $70 \%$ \\
\hline 4 & 0 & 1 & 1 & - & $2.6 \mathrm{~dB}$ & $66 \%$ \\
\hline 5 & 1 & 0 & 0 & $\begin{array}{l}\text { Single } \\
(17-18 \\
\mathrm{GHz})\end{array}$ & $2.8 \mathrm{~dB}$ & $68 \%$ \\
\hline 6 & 1 & 0 & 1 & $\begin{array}{l}\text { Triple } \\
\text { Notch } \\
(6-8.5, \\
9-10 \\
\text { and 11- } \\
14.5 \\
\text { GHz) }\end{array}$ & $3.2 \mathrm{~dB}$ & $74 \%$ \\
\hline 7 & 1 & 1 & 0 & - & $2.5 \mathrm{~dB}$ & $65 \%$ \\
\hline 8 & 1 & 1 & 1 & $\begin{array}{l}\text { Triple } \\
\text { Notch } \\
(7-7.4, \\
8-12 \\
\text { and 16- } \\
18 \\
\text { GHz) }\end{array}$ & $3.4 \mathrm{~dB}$ & $76 \%$ \\
\hline
\end{tabular}

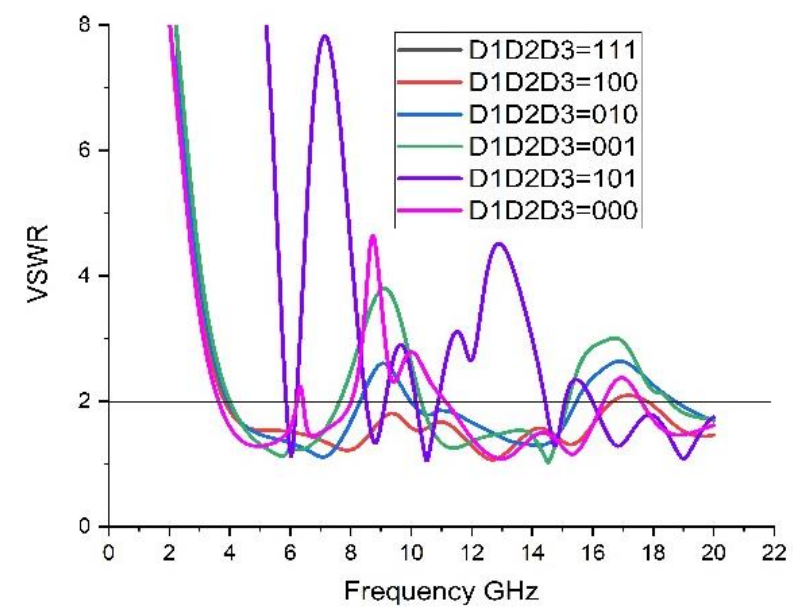

Figure. 11 Frequency reconfigurability of the proposed antenna

\section{Acknowledgments}

Authors like to acknowledge department of ECE of AITAM, ANITS and Andhra University for their encouragement and support during this work.

\section{References}

[1] K. Shan, C. L. Ruan, and L. Peng, "Compact UWB antenna with band-notched characteristic using a coupling strip", In: Proc. of International Symposium on Intelligent Signal Processing and Communication Systems, pp. 14, 2010.

[2] M. Sefidi, Y. Zehforoosh, and S. Moradi, "A novel CPW-fed antenna with dual bandnotched characteristics for UWB applications", Microwave and Optical Technology Letters, Vol. 57, pp. 2391-2394, 2015.

[3] Z. Wang, J. Liu, and Y. Yin, "Triple BandNotched UWB Antenna using novel asymmetrical resonators", International Journal of Electronics and Communications, Vol. 70, No. 12, pp. 1630-1636, 2016.

[4] Z. Tang, J. Zhan, and X. Wu, "Compact triple band-notched printed antenna with multi slots for UWB applications", Microwave and Optical Technology Letters, Vol. 57, pp. 2056-2060, 2015.

[5] J. Kaur, R. Khanna, and M. A. Kartikeyan, "Novel Dual-Band Multistrip Monopole Antenna with Defected Ground Structure for WLAN/ IMT/ BLUETOOTH/ WiMAX Applications", International Journal of Microwave and Wireless Technologies, Vol. 6, No.1, pp. 93-100, 2014.

[6] H. Kaza, and J. Kumar, "Design and Analysis of Compact Coplanar Wave Guide Fed 
Asymmetric Monopole Antennas", Research Journal of Applied Sciences, Engineering and Technology, Vol.10, No 3, pp. 247-252, 2015.

[7] S. S. Huang, J. Li, and J. Z. Zhao, "A Novel Compact Planar Triple-Band Monopole Antenna for WLAN/WiMAX Applications", Progress in Electromagnetics Research Letters, Vol. 50, pp. 117-123, 2014.

[8] A. Nouri and G. R. Dadashzadeh, "A compact UWB band notched printed monopole antenna with defected ground structure", IEEE Antennas and Wireless Propagation Letters, Vol.10, pp. 1178-1181, 2011.

[9] A. M. Abbosh and M. E. Bialkowski, "Design of UWB planar band-notched antenna using parasitic elements", IEEE Transactions Antennas Propagation, Vol. 57, No. 3, pp .796799, 2009.

[10] M. Vijayalakshmi and P. Pardhasaradhi, "A Coplanar Waveguide Fed Asymmetric Ground Frequency Reconfigurable Antenna", International Journal of Intelligent Engineering and Systems, Vol.11, No.4, pp. 293-300, 2018.

[11] K. Murthy, K. Umakantham and K. Satyanarayana, "Reconfigurable Notch Band Monopole Slot Antenna for WLAN/IEEE802.11n Applications", International Journal of Intelligent Engineering and Systems, Vol. 10, No. 6, pp. 166-173, 2017.

[12] T. Li, H. Q. Zhai, G. H. Li, and C. H. Liang, "Design of compact UWB band-notched antenna by means of electromagnetic-band gap structures", Electronics Letters, Vol. 48, No. 11, pp. 608-609, 2012.

[13] M. R Hamid, P. S. Hall, P. Gardner, and F. Ghanem, "Switched WLAN-wideband tapered slot antenna", Electronics Letters, Vol. 46, No. 1, pp. 23-24, 2010.

[14] Y. Li, W. Li, and R. Mittra, "A cognitive radio antenna integrated with narrow/ultra-wideband antenna and switches", IEICE Electronics Express, Vol. 9, No. 15, pp. 1273-1283, 2012.

[15] V. Subbareddy and M. S. G. Prasad, "Triple Band Notch Tree Structured Fractal Antenna for UWB Applications", Journal of Advanced Research in Dynamical and Control Systems, Vol. 9, No. 14, pp. 1755-1763, 2017.

[16] A. Vamseekrishna and B. T. P. Madhav, "A Frequency Reconfigurable Antenna with Bluetooth, Wi-Fi and WLAN Notch Band Characteristics", International Journal of Engineering and Technology, Vol. 7, No. 2.7, pp 127-130, 2018.
[17] B. T. P. Madhav, M. V. Rao, and T. Anilkumar, "Conformal Band Notched Circular Monopole Antenna Loaded with Split Ring Resonator", Wireless Personal Communications, pp. 1-12, 2018.

[18] B. S. Prasad and P. M. Rao, "Trapezoidal Notch Band Frequency and Polarization Reconfigurable antenna for Medical and Wireless Communication Applications", Indian Journal of Public Health Research and Development, Vol. 9, No. 6, pp. 324-328, 2018. 